\title{
FRAGMENTACIÓN DE LOS MECANISMOS DE CONTROL EN EL COMBATE A LA CORRUPCIÓN 1
}

\author{
Adria Velia González Beltrones 2 \\ Guadalupe Aleida Valenzuela Miranda ${ }^{3}$ \\ Miguel Arturo Morales Zamorano ${ }^{4}$ \\ Rafael Ramírez Villaescusa ${ }^{5}$
}

"Toda sociedad en la que no esté asegurada la garantía de los derechos ni determinada la separación de poderes no tiene Constitución" Artículo 16

Declaración de los Derechos del Hombre y del Ciudadano, de1789(SEGOB:1989)

SUMARIO: Introducción. II. 2017. III.2018. IV.2019. V.Conclusiones

\section{RESUMEN}

En el documento se ordena los resultados obtenidos del analisis (a 5 años de distancia) de la implementación del Sistema Nacional Anticorrupción mediante el cual se instituyó un nuevo modelo de responsabilidad administrativa de los servidores públicos en el que se elevó a rango constitucional la distinción, entre faltas administrativas graves y no graves; se ampliaron las facultades de las autoridades encargadas de prevenir, investigar, sancionar y corregir actos de corrupción, que podrán también investigar e imponer sanciones a los particulares, personas físicas o morales, que participen en la comisión de faltas administrativas

\footnotetext{
${ }^{1}$ Los hallazgos y propuestas del tema de investigación de este documento se presentaron en el "2020 Juried Virtual Conference" Western Social Science Association 62nd Annual Conference June 10 through September 30, 2020

2 Docente Investigadora Departamento de Derecho,División de Ciencias Sociales URC,Universidad de Sonora,México, correo electrónico:adria.gonzalez@unison.mx; adriaveliagonzalez@gmail.com

${ }^{3}$ Docente Investigadora,Departamento de Derecho,División de Ciencias Sociales,URC,Universidad de Sonora,México, correo electrónico:aleida.valenzuela@unison.mx

${ }^{4}$ Docente Investigador, D de Sociología y Administración Pública,División de Ciencias Sociales URC,Universidad de Sonora,México, correo electrónico:miguel.morales@unison.mx

${ }^{5}$ Docente Investigador Departamento de Derecho,División de Ciencias Sociales URC,Universidad de Sonora,México, correo electrónico:rafael.ramirez@unison.mx
} 
Fragmentación de los mecanismos de control en el combate a la corrupción Volumen 12, Número 22 ene-jun 2020 González Beltrones, Valenzuela Miranda, Morales Zamorano y Rafael Ramírez Villaescusa

graves y en actos de corrupción; que las faltas graves serán investigadas y substanciadas por los órganos Internos de control de las instituciones de orden

federal o local, en tanto que la determinación de la sanción correspondiente será competencia de los Tribunales Locales y/o Federal de Justicia Administrativa y/o de los juzgados en los que las Fiscalías Especailizadas en Anticorrupción Locales y Federal presenten sus denuncias según corresponda. Por lo que respecta a las faltas administrativas no graves, estas serán investigadas, sustanciadas y resueltas por los Órganos Internos de control, es decir, de estas no conoceran-- en uso de facultades materialmente administrativas las salas especializadas en materia anticorrupción de los Tribunales Locales y Federal de Justicia Administrativa.

Palabras Clave:Infracciones graves, mecanismos de control de la administración, Sistema Nacional Anticorrupción.

\title{
“FRAGMENTATION OF CONTROL MECHANISMS IN THE FIGHT AGAINST CORRUPTION"
}

\author{
Adria Velia González Beltrones \\ Guadalupe Aleida Valenzuela Miranda \\ Miguel Arturo Morales Zamorano \\ Rafael Ramírez Villaescusa
}

SUMMARY: Introduction. II. 2017. III.2018. IV.2019. V. Conclusions

\begin{abstract}
This document orders the results obtained from the analysis (5 years away) of the implementation of the National Anticorruption System by means of which a new model of administrative responsibility of public servants was instituted in which the distinction was raised to constitutional rank, between serious and non-serious administrative offenses. The powers of the authorities in charge of preventing, investigating, punishing and correcting acts of corruption were expanded, which may also investigate and impose sanctions on individuals, individuals or legal entities,
\end{abstract}


who participate in the commission of serious administrative misconduct and in acts of corruption; that serious offenses will be investigated and substantiated by the Internal control bodies of federal or local institutions, while the determination of the corresponding sanction will be the responsibility of the Local and / or Federal Courts of Administrative Justice and / or the courts in which the Federal and Local AntiCorruption Specialized Prosecutors' Offices present their complaints as appropriate. Regarding non-serious administrative offenses, these will be investigated, substantiated and resolved by the Internal Control Bodies, that is to say, of these they will not know - in use of materially administrative powers the specialized anticorruption chambers of the Local Courts and Federal Administrative Justice.

Key Words: Serious offenses, administration control mechanisms, National Anticorruption System.

\section{INTRODUCCIÓN}

El presente tema forma parte de la zaga iniciada en 2017 y 2018 resultado de las investigaciones de los integrantes del Cuerpo Académico Consolidado USON-CAC-205" Derecho, Economía, Educación e Instituciones" a saber: Control Interno de la Administración Pública a la Luz del Sistema Nacional Anticorrupción SNA y ¿Juez y Parte? Ventajas y desventajas del traslado de facultades materialmente administrativas a un órgano formalmente jurisdiccional, presentadas respectivamente en el VII Congreso Internacional y IX Mexicano de Derecho Administrativo, 4 de diciembre de 2017 Ciudad de México, IIJ UNAM y en el VIII Congreso Internacional y $X$ Mexicano de Derecho Administrativo 6 al 7 de diciembre de 2018, Guanajuato, Guanajuato. Universidad de Guanajuato, IIJ UNAM

En ambos eventos se presentaron los siguiente supuestos y resultados que de manera resumida se describen a continuación a efecto de objetivizar el estado del arte de nuestro tema, seguido del marco teórico común y las especificidades por el período 2019, hallazgos y propuestas 


\section{Fragmentación de los mecanismos de control en el combate a la corrupción}

Contexto

A partir de la Reforma Constitucional (2015) que crea el Sistema Nacional Anticorrupción SNA y de la publicación de la legislación secundaria 2016 se establece una nueva regulación en materia de responsabilidades administrativas de los servidores públicos, fiscalización y control de recursos públicos, lo que implicó, entre otras disposiciones, la inclusión, del Tribunal Federal de Justicia Administrativa en el Comité Coordinador del SNA, al que se le otorga la responsabilidad de sancionar a los servidores públicos y a los particulares que participen en faltas administrativas graves.

\section{Problema}

Fraccionamiento de la facultad de sanción que corresponde ejercer al poder ejecutivo y/o a los otros poderes y su transferencia al TFJFA y/o a sus homólogos de las entidades federativas

\section{Hipótesis}

El legislador Constituido... de manera aislada y por separado sin tomar en cuenta la división de poderes y funciones encomendadas primordialmente a cada uno de ellos --- sustrajo arbitrariamente parte de las facultades que en materia de control interno ... debe, en forma integral, corresponder ejercer doctrinaria y legalmente en nuestro país, a la Secretaría de la Función Pública, a la Secretaría de Hacienda y Crédito Público ...a los órganos de control internos de cada una de las dependencias y entidades, que conforman a la administración pública federal... Poder Judicial y los Organismos Autónomos reconocidos expresa o tácitamente en nuestra CPEUM... en las leyes orgánicas que los crean... y de sus homólogos en las entidades federativas.

\section{Metodología}

A fin de demostrar o no, nuestra hipótesis se pasó a examinar los dispositivos jurídicos con ella relacionados en contraste con la teoría aplicable.Se tomó de referencia a la Ley General de Responsabilidades Administrativas, ... no obstante que las entidades federativas debieron durante el año de vacatio legis, alinear su legislación, al SNA, para conformar con disposiciones equivalentes, sus Sistemas locales Anticorrupción ... 
Tabla Número 1:Órganos competentes en materia de Responsabilidades Administrativas

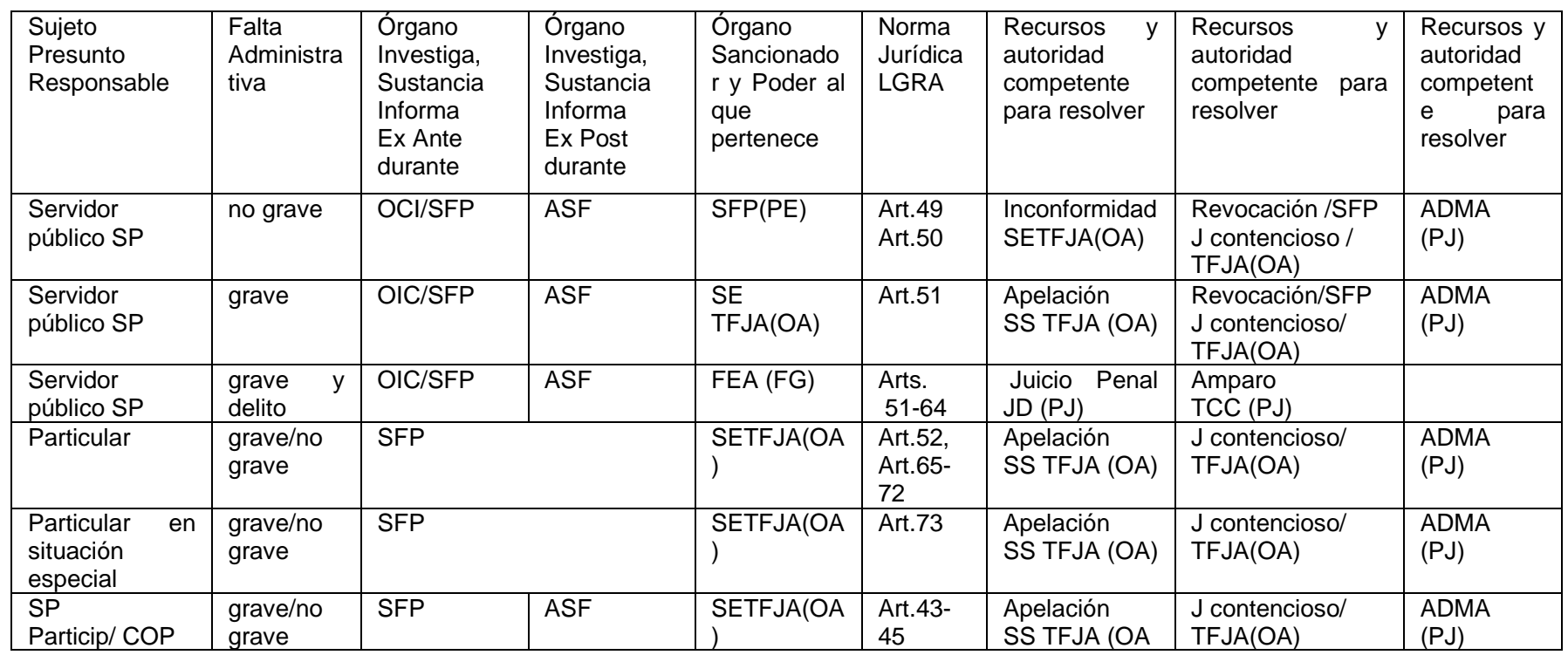

Elaboración propia con datos tomados de los ordenamientos que en la tabla aparecen

Tabla Número 2: Posiciones respecto a la encomienda de los Poderes

\begin{tabular}{|c|c|c|c|c|}
\hline $\begin{array}{l}\text { Teoría Clásica de la } \\
\text { División de Poderes } \\
\text { (Fernandez y } \\
\text { Aragón,2014) }\end{array}$ & $\begin{array}{l}\text { País/ } \\
\text { Época }\end{array}$ & $\begin{array}{l}\text { Grecia Antigua } \\
34 \text { A.C. }\end{array}$ & $\begin{array}{l}\text { Jon Locke } \\
\text { Inglaterra SXVII }\end{array}$ & $\begin{array}{l}\text { Charles de Secondat, barón } \\
\text { de la Bréde y de Montesquieu } \\
\text { Francia S XVIII }\end{array}$ \\
\hline Conceptualización & & $\begin{array}{l}\text { En todas las } \\
\text { constituciones hay } \\
\text { tres elementos con } \\
\text { referencia a los } \\
\text { cuales ha de } \\
\text { considerar el } \\
\text { legislador diligente } \\
\text { lo que conviene a } \\
\text { todo régimen de } \\
\text { estos tres } \\
\text { elementos, uno es } \\
\text { el que delibera } \\
\text { sobre los asuntos } \\
\text { comunes; el } \\
\text { segundo es el } \\
\text { relativo a las } \\
\text { magistraturas; y el } \\
\text { tercer elemento es } \\
\text { el Poder Judicial }\end{array}$ & $\begin{array}{l}\text { Identifica en el } \\
\text { Estado tres } \\
\text { poderes: el } \\
\text { Legislativo, el } \\
\text { Ejecutivo y el } \\
\text { Federativo y } \\
\text { enfatiza la } \\
\text { necesidad de que } \\
\text { los dos primeros } \\
\text { no se } \\
\text { encomienden al } \\
\text { mismo sujeto. }\end{array}$ & $\begin{array}{l}\text { En todo Estado hay tres } \\
\text { clases de poderes: el Poder } \\
\text { Legislativo, el Poder Ejecutivo } \\
\text { y el Poder Judicial, y con gran } \\
\text { claridad plantea el problema } \\
\text { que entraña el peligro en que } \\
\text { se encuentra la libertad } \\
\text { pública, cuando todos los } \\
\text { poderes del Estado se reúnen } \\
\text { en manos de un solo } \\
\text { depositario, sin importar que } \\
\text { sea un individuo o una } \\
\text { asamblea, pues uno u otra } \\
\text { asumen todos los poderes, de } \\
\text { suerte que adquieren una } \\
\text { potestad sin límites, por no } \\
\text { tener el contrapeso de otra } \\
\text { potestad que limite la suya, }\end{array}$ \\
\hline
\end{tabular}

Elaboración propia con datos tomados de (Fernández y Aragón:2014 
Fragmentación de los mecanismos de control en el combate a la corrupción

Volumen 12, Número 22 ene-jun 2020 González Beltrones, Valenzuela Miranda, Morales Zamorano y Rafael Ramírez

Villaescusa

Tabla Número 3a:Conceptualización de las Funciones Legislativa, Ejecutiva y Judicial

\begin{tabular}{|c|c|c|c|c|}
\hline $\begin{array}{l}\text { Teoría } \\
\text { Moderna de } \\
\text { Separación de } \\
\text { Funciones } \\
\text { (Fernández y } \\
\text { Aragón,2014). }\end{array}$ & $\begin{array}{l}\text { País/ } \\
\text { Época }\end{array}$ & $\begin{array}{l}\text { Carré de } \\
\text { Malberg,R.(1920) } \\
\text { Francia 1SXX }\end{array}$ & $\begin{array}{l}\text { Díez M.M } \\
\text { (1967) } \\
\text { Argentina SXX }\end{array}$ & $\begin{array}{l}\text { Fernández- } \\
\text { Ruiz,J.,Aragón,M.I.(2014) } \\
\text { México SXXI }\end{array}$ \\
\hline & & $\begin{array}{l}\text { Las funciones del } \\
\text { poder son las diversas } \\
\text { formas bajo las cuales } \\
\text { se manifiesta la } \\
\text { actividad dominadora } \\
\text { del Estado; dictar la } \\
\text { ley, por ejemplo, es } \\
\text { uno de los modos de } \\
\text { ejercicio de la potestad } \\
\text { estatal, o sea una } \\
\text { función del poder. Los } \\
\text { órganos del poder son } \\
\text { los diversos personajes } \\
\text { o cuerpos públicos } \\
\text { encargados de } \\
\text { desempeñar las } \\
\text { diversas funciones del } \\
\text { poder. El cuerpo } \\
\text { legislativo, por ejemplo, } \\
\text { es el órgano que } \\
\text { desempeña la función } \\
\text { legislativa del poder } \\
\text { estatal. } \\
\text { Las funciones públicas } \\
\text { vienen a ser las } \\
\text { diversas actividades } \\
\text { del Estado que } \\
\text { conllevan el ejercicio } \\
\text { de su potestad. }\end{array}$ & $\begin{array}{l}\text { "el término } \\
\text { función pública } \\
\text { debe } \\
\text { reservarse para } \\
\text { designar los } \\
\text { modos } \\
\text { primarios de } \\
\text { manifestarse la } \\
\text { soberanía, de } \\
\text { donde la } \\
\text { numeración } \\
\text { primaria de las } \\
\text { funciones del } \\
\text { Estado, } \\
\text { legislativa, } \\
\text { ejecutiva y } \\
\text { judicial" }\end{array}$ & $\begin{array}{l}\text { Función pública es la } \\
\text { actividad esencial y } \\
\text { mínima del Estado } \\
\text { contemporáneo, fundada } \\
\text { en la idea de soberanía, } \\
\text { que conlleva el ejercicio de } \\
\text { potestad, de imperio, de } \\
\text { autoridad --de donde su } \\
\text { indelegabilidad--, cuya } \\
\text { realización atiende al } \\
\text { interés público, entre las } \\
\text { que destacan la función } \\
\text { legislativa, la función } \\
\text { jurisdiccional y la función } \\
\text { administrativa. }\end{array}$ \\
\hline
\end{tabular}

Elaboración propia con datos tomados de (Fernández y Aragón:2014) 
Tabla Número: 3b:Conceptualización de las Funciones Legislativa, Ejecutiva y Judicial

\begin{tabular}{|c|c|c|}
\hline \multicolumn{3}{|c|}{ Funciones desde el p/v Formal } \\
\hline $\begin{array}{l}\text { Legislativa } \\
\text { Es la actividad que el } \\
\text { Estado realiza por } \\
\text { conducto de los } \\
\text { órganos que de } \\
\text { acuerdo con el } \\
\text { régimen } \\
\text { constitucional forman } \\
\text { el Poder Legislativo". }\end{array}$ & $\begin{array}{l}\text { Jurisdiccional } \\
\text { Es la actividad que el } \\
\text { Estado realiza por } \\
\text { conducto de los órganos } \\
\text { que de acuerdo con el } \\
\text { régimen constitucional } \\
\text { forman el Poder } \\
\text { Jurisdiccional. }\end{array}$ & $\begin{array}{ll}\text { Administrativa } & \text { o } \\
\text { Ejecutiva } & \\
\text { Es la actividad que } \\
\text { el Estado realiza por } \\
\text { conducto de los } \\
\text { órganos que de } \\
\text { acuerdo con el } \\
\text { régimen } \\
\text { constitucional } \\
\text { forman el Poder } \\
\text { Ejecutivo. }\end{array}$ \\
\hline \multicolumn{3}{|c|}{ Funciones desde el p/v Material } \\
\hline $\begin{array}{l}\text { Legislativa } \\
\text { La que produzca } \\
\text { normas jurídicas } \\
\text { generales, } \\
\text { abstractas, } \\
\text { impersonales, } \\
\text { obligatorias } \\
\text { coercitivas. y } \\
\text { prescindencia de del } \\
\text { órgano que la ejerza. }\end{array}$ & $\begin{array}{l}\text { Jurisdiccional declarar } \\
\text { el derecho, aplicar la ley } \\
\text { en caso de controversias } \\
\text { o conflictos suscitados } \\
\text { entre los particulares, } \\
\text { entre éstos y los órganos } \\
\text { del estado, así como en } \\
\text { los surgidos entre los } \\
\text { órganos del estado, } \\
\text { mediante la resolución } \\
\text { respectiva contenida } \\
\text { generalmente en la } \\
\text { sentencia }\end{array}$ & $\begin{array}{l}\text { Administrativa } \\
\text { implica el } \\
\text { cumplimiento del } \\
\text { mandato legal con } \\
\text { miras al logro de los } \\
\text { fines del Estado, } \\
\text { concretamente del } \\
\text { bien público, del } \\
\text { establecimiento y } \\
\text { mantenimiento de la } \\
\text { paz y del orden } \\
\text { público. }\end{array}$ \\
\hline
\end{tabular}

Elaboración propia con datos tomados de (Fernández y Aragón:2014

En este punto se contrasta la Legislación reformada,con la Teoría y se retoma la concepción a partir del principio de que en todo Estado como afirma Montesquieu (1951)

hay tres clases de poderes: el Poder Legislativo, el Poder Ejecutivo y el Poder Judicial, y con gran claridad plantea el problema que entraña el peligro en que se encuentra la libertad pública, cuando todos los poderes del Estado se reúnen en manos de un solo depositario, sin importar que sea un individuo o una asamblea, pues uno u otra asumen todos los poderes, de suerte que adquieren una potestad sin límites, por no tener el contrapeso de otra potestad que limite la suya, 


\section{Fragmentación de los mecanismos de control en el combate a la corrupción}

circunstancia que puede traducirse en la opresión de la población que, de esta suerte, queda a merced de la arbitrariedad, .......... "Todo estaría perdido si el mismo hombre, la misma corporación de próceres, la misma asamblea del pueblo ejerciera los tres poderes; el de dictar las leyes, el de ejecutar las resoluciones públicas, y el juzgar los delitos o los pleitos entre los particulares”... Quien, además para impedir que se traduzca en realidad tan grande riesgo, y lograr que el poder detenga al poder, propone multiplicar los depositarios, a efecto de que no haya un detentador único, pues al repartir entre ellos los atributos de la soberanía se logrará limitar mutuamente la potestad de todos y cada uno de ellos, de suerte que ninguno alcance una potestad excesiva. (pp. 202-203)

En otras palabras: conseguir el equilibrio de poderes, ninguno por encima de otro, aun cuando compartan entre si, la realización material de la actividad que primordialmente les ha sido asignada en la Constitución.

\section{Resultados}

a. En la especie, se autoriza, a los TFJA y a sus homólogos locales, a interferir las funciones de control de la administración pública.Es decir, las contralorías u órganos de control interno OIC,de los entes públicos de los diversos ordenes federal, estatal o municipal, conservarán sus facultades de sanción solo respecto de aquellas conductas consideradas no graves por el legislador Constituido, desvirtuándose con ello la responsabilidad administrativa como el objeto principal de la correlativa facultad de sancionar en caso de incumplimiento, --derivada a su vez del poder disciplinario surgido de la relación de jerarquía--- e igualmente, se contradice la presunción de inocencia ${ }^{6}$ y los principios de la accountability ${ }^{7}$. entendida ésta:

"como la virtud que todo funcionario público debe desarrollar y su contraparte, como mecanismo social mediante el cual un agente debe rendir cuentas a otro agente" lo cual, a mediano y a largo plazo, en la medida que el funcionario público desarrolle la virtud, el mecanismo social solo confirmará lo positivamente realizado.

b. En otras palabras, paradójicamente, pareciera que - con las precitadas Reformas y leyes de ellas derivadas ---se apuesta mas, a que en nuestro país la corrupción permanezca--- y no a la virtud que debe desarrollarse en los servidores públicos y en la sociedad en conjunto para su erradicación, amén del incremento del aparato gubernamental y de recursos destinados a cubrir los "servicios" del personal de las nuevas Salas Especializadas de los Tribunales de Justicia Administrativa Federal y de las EF, las que por lo pronto dese el 19 de julio del presente año 2017 en algunas entidades federativas, devengan emolumentos sin que hasta la fecha hayan sustanciado asunto alguno relacionado con sus "nuevas atribuciones".

\footnotetext{
6 Incorporada por Reformas Constitucionales de 2008 en nuestro Sistema Penal

7 Otro significado "hacerse cargo y ser responsable"
} 


\section{Propuesta}

Dar marcha atrás al fraccionamiento de la facultad de sanción del poder ejecutivo. Es decir, conseguir el equilibrio de poderes, ninguno por encima de otro, aún cuando compartan entre sí la realización material de la actividad que primordialmente les ha sido asignada en la CPEUM.

¿Para qué? - Para evitar que se desnaturalice la relación jurídicojerárquica, supra-subordinación entre el titular del Ejecutivo y los servidores públicos de la Administración Pública Federal APF y en su caso, puedan estos últimos, acudir ante el órgano jurisdiccional correspondiente.

Asimismo, evitar el incremento en el tamaño del aparato gubernamental y de los recursos destinados a cubrir los servicios del personal de las nuevas salas especializadas de los Tribunales de Justicia Administrativa.

Nuestra hipótesis se confirma puesto que el legislador Constituido consideró una forma de definición de estrategias para el combate a la corrupción y la impunidad, de manera no integral, pretendiendo solucionar una problemática de control de la conducta --- transfiriendo funciones materialmente administrativas a un poder creado para realizar funciones materialmente jurisdiccionales---sin que se haya hecho el diagnóstico de la situación que justificase la conveniencia de tal medida.

\section{8}

\section{Contexto}

A tres años de las Reformas Constitucionales (2015) que crean el Sistema Nacional Anticorrupción SNA, los Sistemas Estatales Anticorrupción SEA y de la publicación de la legislación secundaria (2016) se aborda el estudio de la Legislación relativa del Estado de Sonora como estudio de caso .

\section{Problema}

Aumento de instancias, distribución inequitativa de las cargas de trabajo, acrecentamiento de las fases de los procedimientos administrativos no contenciosos de responsabilidades administrativas, al añadirles las fases del procedimiento seguido en sede jurisdiccional, además de la demora en la recuperación de las indemnizaciones por daño patrimonial a los erarios públicos. 


\section{Fragmentación de los mecanismos de control en el combate a la corrupción}

Hipótesis

El contrasentido de segregar ---de los órganos de control interno y/o externo-- facultades materialmente administrativas, para cederlos, a un órgano materialmente jurisdiccional, obedece al hecho de no reconocer a la función de control como parte inherente de la forma de organización llamada administración. Lo anterior, conforme al estudio de caso del Gobierno del Estado de Sonora.

\section{Discusión.}

Determinar las ventajas o desventajas para el Erario Público, al trasladar la facultad administrativa de control interno (Secretaría de la Contraloría General SCG en Sonora) y sus homólogas Secretaría de la Función Pública y restantes EF o de control externo (Instituto Superior de Auditoría Fiscal ISAF en Sonora)(Auditoria Superior de la Federación ASF y sus homólogos en las EF, a una autoridad jurisdiccional (Tribunal de Justicia Administrativa de Sonora y sus homólogos TFJA y los de las demás EF).

\section{Metodología.}

Basado en el análisis comparativo de las fases del procedimiento administrativo no contencioso de responsabilidades administrativas seguido pre y post Reformas Constitucionales nacional y locales, que crean respectivamente el Sistema Nacional Anticorrupción y sus homólogos de las entidades federativas.

Conforme a la Ley de Responsabilidades de los Servidores Públicos del Estado y de los Municipios ---vigente con anterioridad al 18 de julio de 2016--- son ocho etapas que se seguían para entablar responsabilidades administrativas a los servidores públicos que en su caso hubiesen transgredido las normas aplicables en el ejercicio de sus funciones.Sin distinción en cuanto a procedimiento a segiuir tratandose de infracciones grave o no graves.Contrastando con lo anterior, en la nueva Ley Estatal de Responsabilidades ---vigente a partir del 18 de julio de 2016--- son mas de 15 etapas que se siguen para entablar responsabilidades administrativas a los servidores públicos del Estado de Sonora, que en su caso hubiesen transgredido las normas aplicables en el ejercicio de sus funciones, con la diferencia de que los OIC ---tratándose de infracciones graves ----no continuarán con la etapa siguiente (determinación o no de sanción) del procedimiento iniciado, sino que, enviarán los expedientes relativos, para continuar con la tercera etapa, según sea el caso o a la Fiscalía 
General o a la Sala Especializada en materia de Anticorrupción del Tribunal Estatal de Justicia Administrativa, extendiendose con ello, el tiempo en el cual se debiera solucionar todo asunto relacionado con la probable responsabilidad administrativa y/o penal de funcionarios públicos o particulares por infracciones graves a leyes administrativas.

\section{Resultados}

Si bien se considera ventaja 1) que la nueva Ley Estatal de Responsabilidades Administrativas de Sonora en lo que se refiere a la facultad de revisión de los órganos de control---interno y/o externo-- la cual se ha extendido hacia los particulares que incurran en actos vinculados con faltas administrativas graves; 2) se considera desventaja de las precitadas Reformas, el incremento en número y tiempos de las fases a seguir en el procedimiento oficioso de responsabilidades administrativas, además de 3)la complejidad ---que significa dotar a un órgano formalmente jurisdiccional de facultades materialmente administrativas en relación a infracciones graves--- [ puesto que coexiste, en cuanto a infracciones no graves se refiere, el carácter de órgano materialmente jurisdiccional del TFJA y sus homólogos de las EF].

2019

\section{Contexto}

A cinco años de distancia de la reforma constitucional del SNA y la de sus homólogas de los SEA y a tres años de su implementación conforme a la legislación secundaria locales y federal, con ellas relacionadas cabe preguntar ¿Cuál es el estado que guardan para efectos de nuestro tema los órganos encargados del control interno y/o externo locales y federal de los poderes ejecutivo, legislativo, judicial y órganos autónomos en la implementación de las leyes locales y federal de responsabilidades administrativas? ¿Se simplificaron los procedimientos?

\section{Problema}

Complejidad de las actuaciones de los órganos de control interno A partir de la desnaturalización de las funciones ---que conforme a la Teoría de la división de funciones les corresponde realizar, en el camino del combate a la corrupción.Y complejidad y gravoso para los servidores públicos y/o particulares "indiciados" 
Fragmentación de los mecanismos de control en el combate a la corrupción Volumen 12, Número 22 ene-jun 2020 González Beltrones, Valenzuela Miranda, Morales Zamorano y Rafael Ramírez Villaescusa Hipótesis

El legislador Constituido--- de manera aislada y por separado de la realidad fáctica--- no consideró la complejidad y costos que implicaba conforme al Sistema Nacional Anticorrupción instituir un nuevo modelo de responsabilidad administrativa de los servidores públicos.

\section{Marco Teórico}

En este tenor, "con el nacimiento del Estado se reconoce en su gobierno un poder para corregir y sancionar a los gobernados cuya conducta afecte la buena marcha de la organización.... y por la otra, adicional a ese control sobre la población, en el ámbito interno del aparato administrativo se reconoce un poder especial para mantener la disciplina de la organización jerárquica, a fin de que el ejercicio del poder público se ajuste a los valores fundamentales que, en razón del interés general, son previamente establecidos."(Delgadillo,1990). De lo anterior se advierte, que las autoridades sólo pueden hacer lo que la ley les permite o autoriza, y en contra partida los administrados tienen regulada su libertad hasta el límite de la prohibición legal.

En ambos casos, el incumplimiento conlleva sanciones correspondientes, es decir el poder disciplinario derivado de la relación de jerarquía, se ejerce conforme a lo dispuesto por la normatividad previamente establecida, en la cual se determina, a las autoridades competentes, el catálogo de obligaciones y/o prohibiciones de los servidores públicos, las sanciones a aplicar en caso de incumplimiento o transgresión y los procedimientos a seguir, que garanticen el debido proceso para los servidores públicos afectados.

Lo anterior implica "reconocer verdaderos sistemas de control que regulan los poderes de decisión, ejecución, vigilancia, supervisión, control, evaluación y en su caso disciplinario, entre los servidores públicos en el mas alto grado y los jerárquicos subordinados según la función que legalmente corresponda realizar. ${ }^{8}$

8 Vide: Sistemas de Control Socio- Gubernamental. Miguel Arturo Morales Zamorano; Ana Lilia Banda Castro, Adria Velia González Beltrones; Guadalupe Aleida Valenzuela Miranda, Alipia Avendaño Enciso; México, 2010. Editorial UNISON-CONACYT-UNED ISBN 978-607-00-2362-0. 
Los expertos refieren que el control es parte inherente a la función de administración, y en el ámbito del derecho público lo encontramos en la administración y todas sus variantes de estructura formal. Si bien, la centralización administrativa implica la unidad de los diferentes órganos que la componen y entre ellos existe un orden jerárquico de subordinación frente al titular, de coordinación entre sí, y de subordinación en el orden interno ... esta unidad, también se aprecia en la administración paraestatal.

Y es precisamente mediante la relación de jerarquía y la existencia de líneas de autoridad, que se materializan las decisiones dentro de las organizaciones tanto públicas como privadas, desde la planeación, dirección, ejecución, coordinación, control y posterior evaluación. $Y$ en este sentido es que cabe preguntar ¿cuales son los objetivos de la función pública de fiscalización? y la respuesta directamente apunta al control de la administración pública, actividad a ella inherente, para garantizar que sus operaciones se efectúen en congruencia con los planes, programas y presupuestos previamente aprobados, habida cuenta de que según Lanz-Cárdenas(1987) afirma "en el campo de la función pública, por control debe entenderse el acto contable o técnico que realiza un poder, un órgano o un funcionario que tiene atribuida por la ley, la función de examinar la conveniencia o la legalidad de un acto o una serie de actos y la obligación de pronunciarse sobre ellos" (p.32).

En palabras del eminente jurisconsulto $D$ Jorge Fernández Ruiz ${ }^{9}$ uno de los peligros permanentes en todo Estado, históricamente comprobado, es la posible corrupción de los servidores públicos; el propósito de prevenirla y evitarla contribuye a considerar y reconocer a la fiscalización o control patrimonial del Estado como una función pública cuyo ejercicio requiere el desempeño de una actividad técnica $y$ esencial del ente estatal dirigida a vigilar, verificar, comprobar y evaluar las

\footnotetext{
${ }^{9}$ Fernández Ruiz J. Derecho Administrativo y Administración Pública, México, Ed Porrúa,2006, p.32
} 
Fragmentación de los mecanismos de control en el combate a la corrupción Volumen 12, Número 22 ene-jun 2020 González Beltrones, Valenzuela Miranda, Morales Zamorano y Rafael Ramírez Villaescusa

actividades de los órganos, dependencias y servidores públicos a cuyo cargo está el manejo de los fondos, valores, recursos, bienes y derechos del propio Estado.

Lo anterior, implica, que dicha verificación, deba realizarse preventiva o simultáneamente al ejercicio del presupuesto, desde el interior de las instituciones públicas (control interno) encargadas de dicho manejo o, con posterioridad 0 simultáneamente a su ejercicio, desde el exterior de ellas (control externo); lejos de excluirse, los dos, deben complementarse.

\section{Metodología}

A fin de demostrar o no, nuestra hipótesis pasamos a examinar los resultados a nivel local (Estado de Sonora) y federal ---a cinco años de distancia de la reforma constitucional del SNA y la de sus homólogas de los SEA y a tres de su implementación conforme a la legislación secundaria locales y federal, con ellas relacionadas.

Ámbito federal. Se revisó el portal de transparencia del Tribunal Federal de Justicia Administrativa, a fin de encontrar datos relacionados con las funciones que se le atribuyeron a la luz del Sistema Nacional Anticorrupción. Se encontraron Boletines y noticias relacionadas con los Informes que debe rendir cada año el Presidente del Tribunal Federal de Justicia Administrativa, de los años $2018^{10} \mathrm{y}$ $2019^{11}$---que cubren el periodo a estudio--- y algunos datos globales discursivos relevantes, que sirven a nuestro propósito.

\section{Informe 2018}

El monto económico en trámite total, asciende al 31 de octubre de este año, a poco más de seiscientos diecinueve mil trescientos setenta y cinco millones de pesos. En el ámbito jurisdiccional, podemos afirmar que, el Tribunal, no tiene rezago. Cumplimos con el espíritu y la letra del Artículo 17

\footnotetext{
10 Vide: Tribunal Federal de Justicia Administrativa, Segundo Informe 2018 http://www.tfjfa.gob.mx/media/media/pdf/comunicacion_social/discursos/2018/discurso_segundo_in forme.pdf

11 Vide: Tribunal Federal de Justicia Administrativa, Tercer Informe 2019 http://www.tfffa.gob.mx/media/media/pdf/comunicacion_social/boletines/2019/Boletin_6_2019.pdf
} 
constitucional de prestar justicia pronta y expedita. Nuestro personal jurisdiccional emitió al cierre de este periodo, 126 mil 889 sentencias de fondo y sobreseimiento en relación con los más de 180 mil asuntos ingresados. Asimismo, fueron dictados un millón 665 mil acuerdos, oficios y tramites diversos que no generan baja de expediente, se realizaron más de 3 millones 55 mil notificaciones. El Tribunal durante este ciclo (en su inventario inicial) tenía 76 mil 412 expedientes en trámite; hoy informo que a pesar de los crecientes volúmenes de trabajo se redujo esta cantidad a 62 mil 469 expedientes, lo que equivale a una reducción del $18.25 \%$. De las sentencias que se han emitido, quiero subrayar que su eficacia es ponderable por la diferencia entre el número de sentencias recurridas y confirmadas por los órganos del Poder Judicial de la Federación. Durante el periodo 46 mil 880 sentencias fueron impugnadas, de las cuales al cierre del mismo, se han resuelto 21 mil 885, revocándose sólo 4 mil 249 de ellas, lo que representa que únicamente el $9.06 \%$ de las sentencias impugnadas fueron revocadas por el Poder Judicial de la Federación..... La Sala Especializada en Juicio en Línea reportó un inventario inicial de 837 expedientes y en el transcurso del año se recibieron 2 mil 680 demandas nuevas. En este mismo periodo se emitieron 2 mil 40 sentencias.

Informe 2019

El pasado 6 de diciembre de 2019 el Magistrado Carlos Chaurand Arzate Presidente del Tribunal de Justicia Administrativa rindió su Tercer Informe de Actividades en el cual afirma que el monto económico en trámite total asciende, al 31 de octubre pasado, a la cantidad aproximada de setecientos doce mil ciento cuarenta millones de pesos, y que esta institución ha logrado resolver los asuntos que le competen en el ámbito jurisdiccional, al grado de que no tiene rezago alguno. También afirma que se redujo la cantidad de expedientes en trámite en 8.91 por ciento. Por otro lado, el Magistrado Chaurand Arzate destacó que, del total de 119, 331 sentencias dictadas, 36,281 fueron recurridas, de las cuales, al cierre del periodo, se resolvieron 15,073, revocándose únicamente 1,968 de ellas, equivalente a 1.65 por ciento del total de los fallos emitidos, que, en materia de fiscalización, la Auditoría Superior de la Federación no hizo ninguna observación ni recomendación a este órgano jurisdiccional en la Cuenta Pública de 2018.

De la lectura de los extractos de los informes precitados, se observa (2018) la mención de resultados, únicamente en cuanto a la Sala especializada en Juicios en Línea se refiere y no de las restantes. Por lo cual, nos interesa destacar el rubro ---en ambos Informes--- No hay rezago, ya que, con este dato y el obtenido de la búsqueda realizada en el portal del TFJA, nos da soporte para extraer e identificar el número de resoluciones emitidas por la o las Sala(s) especializada(s)en materia 
Fragmentación de los mecanismos de control en el combate a la corrupción Volumen 12, Número 22 ene-jun 2020 González Beltrones, Valenzuela Miranda, Morales Zamorano y Rafael Ramírez Villaescusa

de responsabilidades administrativas SEMARA durante el periodo 2017- a marzo de 2020. Dicha búsqueda arrojó 1211 resoluciones emitidas por las diversas Salas especializadas del TFJA, de las cuales, solo dos fueron emitidas en la materia que nos ocupa y de las cuales se menciona a continuación un extracto:

1) Publicada el $03 / 03 / 2020$ "Según el enunciado de la pestaña "consulta de sentencias públicas," en los rubros Región y Sala se puede observar la denominación: Primera Sala Especializada en Materia de Responsabilidades Administrativas, aun cuando en el proemio de la sentencia 280/18-RA1-01-9, de fecha 15/01/2020 se encuentra listada como: Décimo Tercera Sala Regional Metropolitana y Auxiliar en Materia de Responsabilidades Administrativas Graves. Sala que realmente, es la resolutora de dicho asunto, y no la que se menciona en la "pestaña" precitada del portal digital del TFJA ${ }^{12}$ y que debe tener presente, que dicha actuación es, en su calidad de autoridad materialmente administrativa y no jurisdiccional, por lo que, la actuación con la que se da fin a dicho asunto, se debe diferenciar identificándola como "Resolución Número......" y no como "sentencia"-según se observa en el extracto lineas debajo---, vocablo, este último, que solo se debe utilizar en los asuntos en los que su actuación obedezca a sus funciones ordinarias de origen,materialmente jurisdiccionales.

Sentencia.Mediante la que se resuelven los autos relativos al procedimiento de responsabilidad administrativa en sede jurisdiccional número 280/18-RA1-01-9, seguido en contra del probable responsable

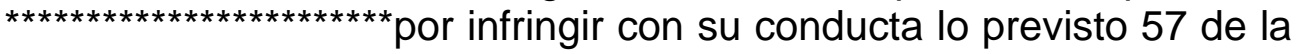
Ley General de Responsabilidades Administrativas.

2) Publicada el 15/01/2020 "Según el enunciado de la "pestaña consulta de sentencias públicas," en los rubros Región y Sala, se puede observar la

\footnotetext{
12 Lo anterior quizás obedece a que, hasta la fecha, aun no han sido nombrados los magistrados de las Salas Especializadas a que se refiere la Ley Orgánica del TFJA en sus artículos 37 al 43. Vide : Un exceso las Salas Especializadas del TFJA; la Constitución no las prevé: Monreal [en línea] Disponible en: https://morena.senado.gob.mx/2019/04/09/un-exceso-las-salas-...
} 
denominación: Primera Sala Especializada en materia de Responsabilidades Administrativas, aun cuando en el proemio de la sentencia 229/18-RAI-01-9 de fecha 30/09/19 se encuentra listada como: Décimo Tercera Sala Regional Metropolitana y Auxiliar en Materia de Responsabilidades Administrativas Grave. Sala que realmente, es la resolutora de dicho asunto, y no la que se menciona en la "pestaña" precitada del portal digital del TFJA ${ }^{13}$ y que debe tener presente, que dicha actuación, es en su calidad de autoridad materialmente administrativa y no jurisdiccional, por lo que, la actuación con la que se da fin a dicho asunto, se debe diferenciar identificándola como "Resolución Número......" y no como "sentencia"-según se observa en el extracto lineas debajo---, vocablo, este último, que solo se debe utilizar en los asuntos en los que su actuación obedezca a sus funciones ordinarias de origen, materialmente jurisdiccionales.

Sentencia.Mediante la que se resuelven los autos relativos al procedimiento de responsabilidad en sede jurisdiccionalnúmero 229/18-RA1-01-9, en el que se tuvo como probable responsable a

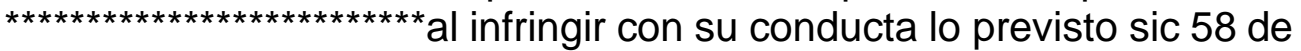
la Ley General de Responsabilidades Administrativas.

De lo anterior se puede colegir que las que hasta ahora fungen como "Salas Especializadas en Materia de Responsabilidades Administrativas del Tribunal Federal de Justicia Administrativa" no tienen claro por lo menos en cuanto a la "forma" la necesidad de distinguir su actuación como autoridad materialmente administrativa de la de autoridad materialmente jurisdiccional.

\footnotetext{
${ }^{13}$ Lo anterior quizás obedece a que, hasta la fecha, aun no han sido nombrados los magistrados de las Salas Especializadas a que se refiere la Ley Orgánica del TFJA en sus artículos 37 al 43. Vide: Un exceso las Salas Especializadas del TFJA; la Constitución no las prevé: Monreal [en línea] Disponible en: https://morena.senado.gob.mx/2019/04/09/un-exceso-las-salas-...
} 
Fragmentación de los mecanismos de control en el combate a la corrupción Volumen 12, Número 22 ene-jun 2020 González Beltrones, Valenzuela Miranda, Morales Zamorano y Rafael Ramírez Villaescusa

Ámbito Local:Estado de Sonora En relación a la Sala Especializada en Materia de Anticorrupción y Responsabilidades Administrativas del Tribunal de Justicia Administrativa del Estado de Sonora TJASON a tres años de su implementación encontramos lo siguiente:

Tabla Número 5: Relación de Asuntos Tramitados y Sentencias Emitidas en la Sala Especializada en Materia de Anticorrupcion y Responsabilidades Administrativas del TJASON

\begin{tabular}{|l|c|c|}
\hline $\begin{array}{l}\text { Juicios, Procedimiento, Recurso, o Medios } \\
\text { de Impugnación }\end{array}$ & $\begin{array}{c}\text { Número de } \\
\text { expedientes } \\
\mathbf{2 0 1 8}\end{array}$ & $\begin{array}{c}\text { Número de } \\
\text { Sentencias } \\
\mathbf{2 0 1 8}\end{array}$ \\
\hline $\begin{array}{l}\text { Juicios Administrativos } \\
\begin{array}{l}\text { Impugnaciones } \\
\text { (Responsabilidad Administrativa,conforme al } \\
\text { artículo 85 de la Ley de Responsabilidades de } \\
\text { los Servidores Públicos del Estado y de los } \\
\text { Municipios) }\end{array}\end{array}$ & 55 & 39 \\
\hline $\begin{array}{l}\text { Juicios de Nulidad } \\
\text { (Responsabilidad Administrativa,conforme a la } \\
\text { Ley de Responsabilidades de los Servidores } \\
\text { Públicos del Estado y de los Municipios) }\end{array}$ & 16 & 03 \\
\hline $\begin{array}{l}\text { Procedimientos de Responsabilidad } \\
\text { Administrativa } \\
\text { (Conforme a la nueva ley Estatal de }\end{array}$ & 6 & 00 \\
Responsabilidades) & & 03 \\
\hline Recurso de Revisión Fiscal & 32 & 74 \\
\hline Total & 339 & \\
\hline
\end{tabular}

Elaboración propia con datos tomados del Informe 2018 del TJAde Sonora

Tabla Número 6: Relación de Asuntos Tramitados y Sentencias Emitidas en la Sala Especializada en Materia de Anticorrupcion y Responsabilidades Administrativas del TJASON 


\begin{tabular}{|l|c|c|c|c|}
\hline \multicolumn{1}{|c|}{$\begin{array}{c}\text { Juicios, Procedimiento, Recurso, } \mathbf{0} \\
\text { Medios de Impugnación }\end{array}$} & $\begin{array}{c}\text { Número de } \\
\text { expedientes } \\
\mathbf{2 0 1 9}\end{array}$ & $\begin{array}{c}\text { Número de } \\
\text { expedientes } \\
\text { acumulados } \\
\mathbf{2 0 1 8 / 2 0 1 9}\end{array}$ & $\begin{array}{c}\text { Número de } \\
\text { Sentencias } \\
\mathbf{2 0 1 9}\end{array}$ & $\begin{array}{c}\text { Número de } \\
\text { sentencias } \\
\text { acumulados } \\
\mathbf{2 0 1 8 / 2 0 1 9}\end{array}$ \\
\hline $\begin{array}{l}\text { Juicios Administrativos } \\
\text { Impugnaciones }\end{array}$ & $\mathbf{1 5 0}$ & 380 & 193 & 232 \\
\hline Juicios de Nulidad & 26 & 94 & 34 & 63 \\
\hline $\begin{array}{l}\text { Procedimientos de Responsabilidad } \\
\text { Administrativa }\end{array}$ & 43 & 42 & 07 & 10 \\
\hline Recurso de Revisión Fiscal & 60 & 92 & 31 & 31 \\
\hline Recurso de Reclamación & 08 & 08 & 68 & 71 \\
\hline Total & 326 & 665 & 337 & 411 \\
\hline
\end{tabular}

Elaboración propia con datos tomados del Informe 2019 del TJAde Sonora

Según es dable apreciar,en las precedentes Tablas Números 5 y 6 :

1) Es en la Tabla Número 5, con datos del Informe del Año 2018, en la que se distingue, mediante subrubros, los asuntos tramitados conforme a la legislación anterior (333) y conforme ala vigente (6) .

2) En ambas Tablas 5 y 6 , con datos de los Informes $2018^{14}$ y $2019^{15}$ se observa que se usa el término sentencia para hacer referencia a los asuntos que llegan a su fin.Sin distinguir a) entre los casos del rubro: Procedimientos de Responsabilidad Administrativa 2018 (0) 2019 (31) que deberian concluir con una resolución materialmente administrativa y no jurisdiccional y en los restantes casos como en la especie sucede, concluir con sentencias interlocutorias 2018 (32), 2019 (106), o con sentencias definitivas: 2018 (54) 2019 (200) según Informes.

3) Es importante la distinción puesto que las resoluciones materialmente administrativas y no jurisdiccionales de la SEARA,en caso de no ser favorables al servidor público o particular relacionado con faltas graves, se podrán posteriormente combatir, mediante el recurso de Apelación ante la Sala Superior del propio TJASON ¿Juez y Parte? Artículo 101 Bis Ley de Justicia Administrativa LJASON.

4) En la página 14 Primer Párrafo del Informe 2019 se da la siguiente

\footnotetext{
14 vide pp. $16-18$

15 vide pp. $12-13$
} 
Fragmentación de los mecanismos de control en el combate a la corrupción Volumen 12, Número 22 ene-jun 2020 González Beltrones, Valenzuela Miranda, Morales Zamorano y Rafael Ramírez Villaescusa

relación:

Del total de 337 la SEARA emitió: 254 Sentencias definitivas.Y respecto de su sentido:confirmó 89 resoluciones de autoridades y anuló 143 resoluciones de autoridades. Además,la Sala Especializada en Procedimientos de Responsabilidad Administrativa conforme a la Ley Estatal de Responsabilidades, ha emitido sentencia condenatoria en cuatro (04), y ha absuelto en cinco (05). Asimismo, con relación a los denominados Juicios Administrativos, se han emitido diez(10), sentencias condenatorias y tres $(03)$ sentencias absolutorias.

5) Asimismo, la SEARA del TJASON, mediante resoluciones definitivas,concluyó (83) Juicios, Procedimientos o Recursos en la etapa procesal de instrucción al no cumplir alguna de las partes intervinientes en los mismos,con las cargas procesales contempladas en la ley correspondiente,o,por haberse actualizado alguna causa de improcedencia,sobreseimiento, o que la parte actora, se haya desistido de la acción.

A continuación:

Tabla Número 7, comparativa de los presupuestos de la federaión asignados en los ejercicios fiscales de 2017 a 2020 a diferentes órganos autónomos,dependencias y Ramo 32. 


\begin{tabular}{|l|c|c|c|c|}
\hline \multicolumn{5}{|c|}{ Presupuesto de Egresos de la Federación } \\
\hline \multicolumn{5}{|c|}{$\begin{array}{c}\text { Anexo } 1 \\
\text { Gasto Gasto Neto Total en mn } \\
\text { Arogramable: Ramos Autónomos RA, Ramos Administrativos } \\
\text { RADM,Ramo 32 }\end{array}$} \\
\hline AÑO & 2017 & 2018 & 2019 & 2020 \\
\hline $\begin{array}{l}\text { TFJA } \\
\text { (R32) }\end{array}$ & $2,554,777,815$ & $3,029,044,741$ & $2,695,853,467$ & $2,792,233,371$ \\
\hline $\begin{array}{l}\text { ASF } \\
\text { (RA) }\end{array}$ & $2,275,766,700$. & $2,230,116,964$ & $2,304,444,027$ & $2,378,405,960$ \\
\hline $\begin{array}{l}\text { TEPJF } \\
\text { (RA) }\end{array}$ & $3,125,280,000$ & $3,893,200,000$ & $2,538,604,681$ & $2,648,603,020$ \\
\hline $\begin{array}{l}\text { CNDH } \\
\text { (RA) }\end{array}$ & $1,728,566,039$, & $2,033,004,229$ & $1,809,405,805$ & $1,874,207,802$ \\
\hline $\begin{array}{l}\text { SFP } \\
\text { (RADM) }\end{array}$ & $1,106,575,552$ & $1,191,905,203$ & $901,819,393$ & $1,461,399,636$ \\
\hline $\begin{array}{l}\text { TA } \\
\text { (RADM) }\end{array}$ & $882,205,614$ & $980,961,673$ & $831,402,778$ & $850,645,718$ \\
\hline $\begin{array}{l}\text { INE (RA) } \\
\text { RA }\end{array}$ & $15,071,176,879$ & $24,215,327,986$ & $15,363,037,745$ & $16,660,795,016$ \\
\hline
\end{tabular}

Elaboración propia con datos tomados del Diario Oficial de la Federación

En la Tabla Número 7 de Presupuestos de Egresos de la Federación por los años 2017 a $2020^{16}$ se puede apreciar (con diferencias mínimas en cada ejercicio) lo siguiente:

Para 2017 al Tribunal Federal de Justicia Administrativa TFJA se le otorgó un presupuesto en pesos en cantidad de 2,554,777,815, un poco superior al asignado a la Auditoría Superior de la Federación ASF de 2,275,766,700. Considerablemente menor que el correspondiente al Tribunal Electoral del Poder Judicial de la Federación TEPJF 3,125,280,000 y por encima de los asignados a la

\footnotetext{
${ }^{16}$ Publicados en el DOF :30 de noviembre de 2016, 30 de Nov de 2017, 2018, 28 de Diciembre de 2018, y 11 de Diciembre de 2019 respectivamente
} 
Fragmentación de los mecanismos de control en el combate a la corrupción Volumen 12, Número 22 ene-jun 2020 González Beltrones, Valenzuela Miranda, Morales Zamorano y Rafael Ramírez Villaescusa

Comisión Nacional de Derechos Humanos CNDH 1,728,566,039, a la Secretaría de la Función Pública SFP1,106,575,552 y Tribunales Agrarios 882,205,614.

Para el año 2018 en las cantidades asignadas se puede observar comportamiento similar en las cifras al año 2017, con variaciones en porcentajes moderados, excepto en el asignado al Tribunal Electoral órgano ya inserto en el Poder Judicial Federal que de manera incongruente recibió un incremento superior al asignado al TFJA ¿Por tratarse de año electoral se justifica las cantidades ominosas asignadas?

Para el año 2019 en las cantidades asignadas se puede observar una disminución en su conjunto respecto a lo ejercido en el año 2018 con variaciones en porcentajes moderados, excepto en el asignado al Tribunal Electoral órgano que si bien recibió una cantidad menor que la del TFJA se mantiene por encima de los asignados a la ASF, CNDH, SFP y TA llamando la atención la caída drástica del asignado a la SFP respecto al asignado en los año 2018 y 2017.

Para el presente Año 2020, en la Tabla que nos ocupa, es dable apreciar en su conjunto, una ligera disminución respecto al asignado en el 2019 y a simple vista, incongruencia en las asignaciones presupuestales, si se toma en cuenta la importancia de la actividad y la dimensión en volumen de trabajo y cantidad de personal asignado a cada organismo o dependencia precitados, sin mencionar que organismos autónomos como el Instituto Nacional Electoral aproximadamente ha percibido $(2018,2019$ y 2020$)$ hasta 8 veces mas el presupuesto asignado al TFJA, y a la propia ASF redondeado en las insultantes sumas de $\$ 24,215,327,986$ pesos en el 2018, para el 2019 la cantidad de $\$ \mathbf{1 5 , 3 6 3 , 0 3 7 , 7 4 5}$ y en el 2020 la suma de $\$ 16,660,795,016$.

\section{HALLAZGOS Y PROPUESTAS}

El Sistema Nacional Anticorrupción instituyó un nuevo modelo de responsabilidad administrativa de los servidores públicos en el que se elevó a rango constitucional la distinción, entre faltas administrativas graves y no graves; se ampliaron las facultades de las autoridades encargadas de prevenir, investigar, sancionar y corregir actos de corrupción, que podrán también investigar e imponer 
sanciones a los particulares, personas físicas o morales, que participen en la comisión de faltas administrativas graves y en actos de corrupción; que las faltas graves serán investigadas y substanciadas por los órganos Internos de control de las instituciones de orden federal o local, en tanto que la determinación de la sanción correspondiente será competencia de los Tribunales Locales y/o Federal de Justicia Administrativa y/o de los juzgados en los que las Fiscalías Especailizadas en Anticorrupción Locales y Federal presenten sus denuncias según corresponda. Por lo que respecta a las faltas administrativas no graves, estas serán investigadas, sustanciadas y resueltas por los Órganos Internos de control, es decir, de estas no conoceran los Tribunales Locales y Federal de Justicia Administrativa.

De todo lo expuesto, y documentado, nos lleva a concluir que en el caso a estudio, se observa la desnaturalización de las funciones que conforme a la Teoría de la división de funciones les corresponde realizar--- en el camino para combatir la corrupción---a los órganos de control interno/externo de las instituciones, así como a los encargados de la justicia administrativa en la parte contenciosa, tratándose de infracciones graves, toda vez que: 1) de un lado se aumenta, en número y tiempos, las fases a seguir en el procedimiento oficioso de responsabilidades administrativas, en sede administrativa, desdoblando a esta, en una sede "materialmente fiscal" al fungir como "investigadora" y en una sede "materialmente judicial" al fungir como "sustanciadora" y 2) en contrapartida lo que debiera ser un procedimiento contencioso de responsabilidades administrativas llevado ante los Tribunales de Justicia Administrativa locales y/o su homólogo federal --- sedes de origen, materialmente jurisdiccionales--- tratándose de infracciones graves, las Salas especializada en materia de anticorrupción y/o de responsabilidades administrativas SEARA, ${ }^{17}$ se convierten en sede materialmente administrativa, y conservan en relación a infracciones no graves, su facultad de

17 En el ámbito federal se denomina Sala especializada en materia de responsabilidades administrativas, en el Estado de Sonora se le da el nombre de Sala especializada en materia de anticorrupción y responsabilidades administrativas. 


\section{Fragmentación de los mecanismos de control en el combate a la corrupción}

Volumen 12, Número 22 ene-jun 2020

González Beltrones, Valenzuela Miranda, Morales Zamorano y Rafael Ramírez

Villaescusa

origen, materialmente jurisdiccional.

Lo descrito en el párrafo precedente, ya en sí, significa mayor cantidad y complejidad de trámites que actualmente se realizan, comparados con los que antes realizaban los órganos de control interno/externo de las instituciones, en materia de responsabilidades administrativas. Lo mas grave, es hacer nugatorio, tanto para la autoridad emisora del acto, como para el particular afectado con dicho acto, las señaladas doctrinariamente ${ }^{18}$ como plausibles ventajas ---de los recurso administrativos contemplados en las Leyes de la materia--- ya que con las nuevas Reformas, el servidor público o particular "indiciado" por faltas administrativas graves, deberá primeramente agotar, ya no por si mismo, sino con la intervención de su abogado, ${ }^{19}$ las "fiscalizadas" y "judicializadas" fases de investigación y/o sustanciación ante los órganos de control interno o externo, y deberá esperar a que una vez recibido su expediente, la SEARA emita su resolución materialmente administrativa aplicando la sanción correspondiente, y si no le fuere favorable, en su caso, solo hasta entonces, podrá combatirla ante el Tribunal de Justicia Administrativa o ante el juzgado penal según corresponda. Queda para examinar con detenimiento,en otro tema, el anterior planteamiento para los órganos de control externos locales y su homólogo el federal.

Con lo expuesto en parrafos precedentes, nuestra hipótesis se confirma, al igual que la primera de las preguntas de investigación planteadas puesto que el legislador Constituido, consideró una forma de definición de estrategias para el combate a la corrupción y la impunidad, de manera no holística, pretendiendo

\footnotetext{
18 Vide Margín Manautou, Emilio, El Recurso Administrativo en México,Ed.Porrúa,México,2006pp 1921.Es un eficaz control de legalidad de la actuación de la autoridad administrativa;este medio de defensa le evita al particular un conflicto oneroso,pues el mismo puede ser su propio abogado;el desahogo de las pruebas que se ofrezcan o solicite la autoridad,no se sujetará al tecnisismo propio de un tribunal;permite conocer a la autoridad de aquellas lagunas o fallas de tecnica legislativa; posibilidad de que la autoridad resuelva conforme a justicia y no conforme a derechoya que la autoridad puede tomar en cuenta circunstancias que un tribunal no puede examinar; para el particular si le asiste la razón será mas expedita la justicia administrativa entre otras ventajas.

${ }^{19}$ Artículo 117 y demás relativos de la Ley General de responsabilidades Administrativas LGRA y Artículo 157 y demás relativos de la Ley Estatal de Responsabilidades Administrativas de Sonora LERASON
} 
solucionar,una problemática de control de la conducta, --- con transferir, funciones materialmente administrativas de los órganos de contol interno/externo de las instituciones, a un órgano autónomo creado exprofeso para realizar funciones materialmente jurisdiccionales---sin que se haya hecho el diagnóstico de la situación que justificase la conveniencia de tal medida, máxime que, a la fecha, sigue el proceso de construcción de los Sistemas Nacional y Locales Anticorrupción obstaculizandose, desde dentro y desde fuera su consolidación, a virtud ante,durante y ex post a su nacimiento, de los cambios de autoridades políticas, de orden municipal,local,federal,nacional e internacional.

Nuestra propuesta: Dar marcha atrás,al fraccionamiento de la facultad ---de los órganos de control interno /externo de las instituciones--- de sancionar a los servidores públicos, tratandose de faltas administrativas graves. Es decir, en lugar de fragmentar conseguir el equilibrio de poderes, ninguno por encima de otro, aún cuando en los casos que se justifique, compartan entre sí, la realización material de la actividad que primordialmente les ha sido asignada en la Constitución Politica de los Estados Unidos Mexicanos CPEUM y en las Homólogas Locales.

\section{Referencias Bibliográficas}

DELGADILLO, L H. Derecho Disciplinario de la Función Pública,México, INAP, 1990 DIEZ, M.M. Derecho administrativo, Buenos Aires: Bibliográfica Omeba, t. III.,1967 FERNÁNDEZ-RUIZ J.,ARAGÓN,M.I. Derecho Administrativo del Estado Sonora, México, Porrúa,2014

FERNÁNDEZ RUIZ J., Derecho Administrativo y Administración Pública,México, Porrúa, 2006

MONTESQUIEU, CH.,El Espíritu De Las Leyes, Trad. De Nicolás Estevanez, Buenos Aires, El Ateneo, 1951.

LANZ -CÁRDENAS, J.T.,La Contraloría y el Control Interno en México, México FCE,1987 MARGAÍN-MANAUTOU, E., El Recurso Administrativo En México, México,Porrúa,2006 MORALES, M.A.,BANDA, A.L.,GONZÁLEZ, A.V.,et.al., Sistemas de Control, México: CONACYT-UNISON,2010 
Fragmentación de los mecanismos de control en el combate a la corrupción

Volumen 12, Número 22 ene-jun 2020 González Beltrones, Valenzuela Miranda, Morales Zamorano y Rafael Ramírez Villaescusa

SECRETARÍA DE GOBERNACIÓN,Declaración de los Derechos del Hombre y del Ciudadano, 1789-1989 Bicentenario de La Declaración de los Derechos del Hombre y del Ciudadano,México, SEGOB, 1989

TRIBUNAL FEDERAL DE JUSTICIA ADMINISTRATIVA,Discurso Segundo Informe,2018. Recuperado de http://www.tffa.gob.mx/media/media/pdf/comunicacion_social/discursos/2018/discu rso_segundo_informe.pdf (2019) Boletín Tercer Informe. Recuperado de

http://www.tffa.gob.mx/media/media/pdf/comunicacion_social/boletines/2019/Boletin_6_2 019.pdf

Tribunal de Justicia Administrativa de Sonora (2018) Informe 2018. Recuperado de http://www.Tjasonora8Gob.Mx/Docs/Informe_2018.Pdf (2019) Informe2019. Recuperado de http://www.Tjasonora.Gob.Mx/Docs/Informe_2019.Pdf

Recibido 12 dejunio de 2020 Aceptado 30 de Junio de 2020 